\title{
INVESTIGATIVE COMPETENCES IN HEALTH PROFESSIONALS
}

\author{
Dr. Marlene Hernández Navarro 1, Dra. Amelia Patricia Panunzio 2, Dr. Jorge Elías \\ Dáher Nader ${ }^{1} \boldsymbol{凶}$, Ing. Mario Ángel Royero Moya ${ }^{3}$, Est. Claudia Patricia Fernández \\ Hernández ${ }^{1}$ \\ ${ }^{1}$ Guayaquil University, Ecuador \\ 2 University of Zulia, Venezuela \\ ${ }^{3}$ Miraflores School, Peru
}

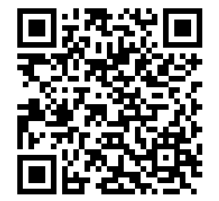

DOI: https://doi.org/10.29121/granthaalayah.v8.i10.2020.1878

Article Type: Research Article

Article Citation: Dr. Marlene Hernández Navarro, Dra. Amelia Patricia Panunzio, Dr. Jorge Elías Dáher Nader, Ing. Mario Ângel Royero Moya, and Est. Claudia Patricia Fernández Hernández. (2020). INVESTIGATIVE COMPETENCES IN HEALTH PROFESSIONALS. International Journal of Research GRANTHAALAYAH, 8(10), 142-146. https://doi.org/10.29121/granthaa layah.v8.i10.2020.1878

Received Date: 30 September 2020

Accepted Date: 28 October 2020

Keywords:

Research Competence

Teacher

Student

\begin{abstract}
Investigative competencies are necessary to carry out an optimal and efficient research process. Descriptive research is presented whose general objective is to design a proposal of investigative competencies in the areas of the study plan of the medical career. The specific objectives are: to characterize the teachers and students of the medical career, identify the research activities in progress, describe the scientific and technical competences for the performance of the research and design a proposal of investigative competences in the three areas of the plan of study of the medical career of an Ecuadorian university.
\end{abstract}

\section{INTRODUCTION}

The relationship between teaching and research has been considered an essential interaction space throughout the history and development of education, therefore the quality of educational institutions is evaluated nationally and internationally, on the basis of various criteria, of which one of the most important is related to the research activity of teachers, the execution of projects, the products of research, among other indicators (Hernández, 2002). In this sense, research constitutes the central axis of academic work and becomes the mode of instruction, so that, for teachers, a relationship of endless commitments is generated with the advancement of scientific knowledge and the culture of humanity, relating to very narrow form: teaching and research. (Hernández, 2002)

It is currently a necessity to integrate training and research as a vital necessity in the graduation of professionals prepared to give the correct answers to the growing social demands, based on this not only by the positive influence of learning based on scientific research, but also because of the transformative potentialities that can be achieved in 
educational processes in which research and teaching constitute a strong and indissoluble union. In order to achieve optimal results in this relationship, it is required that continuous training in teaching competencies in Higher Medical Education is permeated not only with the most positive heritage of the traditional, but also with an innovative spirit, with the demands of pedagogy. contemporary and therefore of a renewed model. (Parra, 2015).

The training-research binomial needs teachers with experience and expertise who have research skills that are at the disposal of the educational process in which they develop, to transform it, taking into account the existing characteristics in the various contexts under study, without losing sight of since it is not an easy and automatic process and that to achieve it it has to be built in teaching areas focused on that nexus. (Marsh and Hattie, 2002)

The scientific competences in teachers allow the application of knowledge and skills in their professional practice, with main emphasis on the epistemological, methodological, technical and social dimensions. The above requires the design and implementation of procedures for investigative work from the teaching activity that allow establishing actions that guarantee the training and development of research in students, as well as the increase of investigative activity in the teaching staff.

\section{DEVELOPING}

Continuous teacher training in higher education has been strengthened but still with limitations focused on: no employment and inadequacies in teaching-learning strategies; lack of the guiding role for the development of investigative skills, among others. There is still a need to enhance research competencies for the continuous improvement of Higher Education institutions. (Barrera, R. H. 2018)

The development of research competence in education has been debated for several decades, many scholars on the subject agree that they allow university graduates to provide solutions to professional problems from a scientific and investigative conception. Their training and development is conditioned by the curriculum of a university career that responds to interests, needs and demands of society and the personal resources that the individual possesses; too. (Barrera, 2018)

The early incorporation of the scientific method by students is crucial for the development of research competencies, from undergraduate, which enhances the acquisition of research skills, at the same time familiarizes them with research and creates a research culture in them. In Ecuador, several authors attribute insufficient scientific production to various factors, among which the lack of motivation on the part of the faculty and of incentive to attract students to the world of research stands out. (Hernández, Losada, 2017). At this point it is worth asking

Are university teachers endowed with the necessary and sufficient investigative skills to train and develop investigative skills in students?

The training of teachers in Latin America was permeated by positivism and in particular by constructivist considerations that were introduced from various countries in Europe and the United States of America, from where specialists arrived to train teachers, especially at the superior in the formation of investigative competences. (Soto, 2017)

There are barriers in university processes, especially with regard to research management and organizational culture in this area. These barriers prevent structuring the research activity from the preparation of teachers in the area of research methodology, on the other hand, there is a traditional myth of considering research at levels higher than those that students should undertake, which results in in the lack of didactic research training strategies from the first years of university training.

Marsh and Hattie (2017) point out the lack of correlation between the effectiveness of teaching and the productivity of research, a product of the evident dissociation between teachers and researchers in terms of the competencies that each professional group must have in those categories ( teaching and research), a statement that urges both groups to achieve both pedagogical and investigative competencies that allow the training-research nexus.

In medical education, Ruiz de Gauna et al. (2015), referring to the formation of competencies, propose strategies that employ a hermeneutical perspective with methodologies such as learning based on problem solving and insist on project-oriented learning. Such elements should consider, however, possible transformations in the curriculum, which could be understood in the integration to the latter of axes or central transversal themes in which the investigative tools are shown as a substantive element in the training " 
The training process in medical education has three dimensions: teaching, care and research. This process should prepare future professionals to face and solve problem situations that are unpredictable. These two points of view are essential to understand the need to develop research competence7 in health professionals, assuming it as the ability to solve problems in the research process with a reflective, critical and flexible stance, which implies having a set of knowledge, skills and attitudes specifically referred to the procedural part of the investigation. (Church, 2012)

Consequently, investigative competence can be measured at the level of performance, (Salas, 2005 and Tobón, 2013) expressed specifically in the behavior and aptitude of the health professional with the use of the knowledge and resources available to carry out a task or activity, efficiently face and solve a situation in a particular and critical way.

It is also necessary that the study plans provide spaces for research and establish as transversal curricular axes the theme of research in the training of professionals. The leading role of the university professor in the research process should be emphasized, which must be present in all teaching activities, such as. The above indicates the need to think about the research from the teaching performance (Mur, Casanova, Iglesias and Cortés, 2014). The performance of the university teacher in the field of medical education currently constitutes a new challenge for higher education; it translates into greater individual and institutional commitment to achieve performance in accordance with quality standards.

Teaching in Medicine in Ecuador has traditionally been developed by vocation and motivation of different professionals who, despite not having pedagogical training, are eager to maintain scientific interest; However, on some occasions there is not a solid pedagogical, investigative and didactic foundation that allows the teacher to function with quality in this area. However, the fact that a professor of medical sciences has not received training as a teacher does not necessarily imply that he is teaching poor quality. In very few Opportunities It is possible to discuss and reflect on the importance of the role played by the trainers of the medical resource and what their main characteristics should be. The preparation of human resources for health is a delicate process as it involves the training of a professional whose mission is none other than to ensure the health and lives of people. Since they (health and life) are the most precious assets of any individual, it is essential to make the best conditions available to future professionals for their proper training.

It is a current requirement of Medical Education "to considerably increase the supply of qualified teachers, endowed with investigative competences, including through international cooperation for the training of teachers in developing countries, especially the least developed countries and small island developing states" (UN, 2015, p. 20).

With regard to teaching in Health Sciences, there are two aspects that require attention: education and training. This is how the human character that demands the fulfillment of teaching activity is approached, in a society marked by the tendency towards individuality and a behavior marked by current social problems. Taking into account the delicate work of teachers, focused on knowledge, the competencies acquired throughout life and, above all, responsibility for the well-being of students, these types of regulations create instruments for dialogue between the various actors in the process educational and should be mandatory for the improvement of education in general. (Salas P, 2015)

Teaching in higher education is maintained thanks to a rigorous effort of study and research throughout life: it is a form of public service that requires deep knowledge and specialized knowledge from higher education teaching staff; It also requires a sense of personal and institutional responsibility in the task of providing education and wellbeing to students and the community in general, as well as to achieve high professional levels in study and research activities (UNESCO, 2009, p. 11) .

It is worth asking, then, is it necessary to redirect the work of the teacher from critical and investigative pedagogical reflection in line with current trends in medical education?

The work of the health sciences teacher is to ensure throughout the training period the habit of reflecting deeply on what is studied and transmitting a research culture of analysis and reflection to their students, one of the ways to achieve this is by exercising thought critic in the classroom. It is a current need in the didactics of medical science careers to implement an active developer teaching that stimulates the cognitive independence of students and prepares them to solve problems with a critical and reflective attitude. The active learning of which Comenio and Pablo Freire were the first exponents offers necessary and sufficient tools for continuous personal and professional improvement of students from the particular didactics of the subjects of health sciences, which constitutes a quality guarantee for the institution of higher education. 
The assimilation and early practice of the scientific method by students from undergraduate is necessary. Research should be a transversal and longitudinal axis throughout the curriculum, this favors the formation and development of investigative skills, while contributing to the development in them of an investigative culture and a marked interest in research. (Hernández, Losada, 2018).

Higher education must train critical, reflective and analytical citizens, so that they can develop in accordance with the claims and needs demanded by the third millennium and, above all, intend an honest performance; thus society is rewarded in a fair and equal manner. It is about achieving reflective skills, critical thinking, investigative and communication skills in the student, reinforcing the competence of learning to learn. For this, the university must be a leader in its training activities and give priority to student learning in which teachers are, of course, embedded. In correspondence with what has been proposed, the processes Training courses must be coherent and adjusted to the real needs of the educational system to which they respond.

The higher education teacher must prepare to investigate their reality and propose alternative solutions to the educational problems that arise in their daily practice. However, many teachers are not sufficiently aware of this fact, since they consider research as an overload that they do not assume thanks to insufficient preparation. (Gonzáles, 2017)

The higher or university education level demands from the student new ideas, concepts, abstract and universal points of view and a tendency to research that challenge him in his traditional way of studying and in his narrow vision of life; hence the need to develop scientific and critical thinking as a skill for their own cognitive development.

A measurer of the investigative competences of teachers and students is the scientific production. The low scientific production that universities have, especially medical schools, and especially in medical education (Doja, Horsley, Sampson, 2014) is a current problem in Latin America, so much so that there have been few reports of scientific production of every country in this area. This low production in medical education in Latin America with respect to other areas may be due to the lack of funding, incentives, and research training programs in this area (Morán and Taype, 2017).

\section{CONCLUSIONS}

To develop quality research in the university environment, both teachers and students need to be endowed with investigative skills that allow them to perform optimally in the context in which they operate. During the training process of students in the health sciences, the development of their scientific skills is as important as that of their clinical skills, since knowledge of the scientific method and its application during research actions is central to healthcare work future as professionals.

\section{SOURCES OF FUNDING}

This research received no specific grant from any funding agency in the public, commercial, or not-for-profit sectors.

\section{CONFLICT OF INTEREST}

The author have declared that no competing interests exist.

\section{ACKNOWLEDGMENT}

None.

\section{REFERENCES}

[1] Barrera, R. E. (2018). The investigative competences of the university professor. University and Society, 10 (4), 75-84. Retrieved from https://rus.ucf.edu.cu/index.php/rus/article/view/980/1043 
[2] Doja, Horsley and Sampson, (2014). Productivity in medical education research: an examination of countries of origin. BMC Med Educ.; 14: 243

[3] González, Y E (2017). How to evaluate the investigative competence from the university social responsibility? Rev. Cubana Edu. Superior vol.36 no.2 Havana May-Aug.

[4] Hernández P (2002). Teaching and research in higher education. Journal of Educational Research, 2002, Vol. 20, No. 2, pp. 271-301. Retrieved from: file: /// C: /Users/User-PC/Downloads/98921Texto\%20del\%20art\%C3\%ADculo-397111-1-10-20100315.pdf

[5] Hernández and Losada. (2017). On the subject of student scienti fi c research in Ecuadorian medical education. www.elsevier.es/edumed

[6] Iglesias R M (2012). The Research Competition. Interview about tutoring to Educational Research. Havana.

[7] Marsh HW, Hattie J. (2002). The relation between research productivity and teaching effectiveness complementary antagonistic, or independent constructs? J High Educ [Internet]; 73: 603 --- 41 [accessed November 14, 2017].

[8] Morán, Taype, (2017). Scientific production in medical education in Latin America at Scopus. DOI: 10.1016 / j. edumed.

[9] Mur, Casanova, Iglesias, Cortés, (2014). Scientific policy in the training of professionals in the medical sciences. A thoughtful look. Medisur [magazine on the Internet]. [12 (1): [approx. 4 p.]. Retrieved from http://www.medisur.sld.cu/index.php/medisur/article/view/2758

[10] United Nations Organization for Higher Education, Science and Culture (2009). World Conference on Higher Education: The new dynamics of higher education and research for social change and development (UNESCO Headquarters, Paris)

[11] Parra, AH (2015). The competences of the medical teacher and their implications in the academic performance of the doctor in training. PEARSON, Mexico.

[12] Ruiz G P, González MV, Morán B J. (2015). Ten pedagogical keys to promote good practices in medical training based on competencies in the degree and specialization. Educ Med [Internet]; 16: 34 --- 42 [consulted 14 December 2017].

[13] Salas R. (2005). Evaluation of professional performance. Proposal for a model. Havana: National School of Public Health.

[14] Salas, R. S., Díaz, L., and Pérez, G. (2013). Standardization of job competencies for medical specialties in the national health system. Higher Medical Education, 27 (2), 287-293. Retrieved from http://scielo.sld.cu/scielo.php?script=sci_arttext\&pid=S0864-21412013000200015\&lng=es\&tlng=es.

[15] Soto A D (2017). Teacher training and pedagogical model at the Pedagogical and Technological University of Colombia. Magazine. 